Gök, İ., Y., Teker, T., Taşan, B. / Journal of Yasar University, 2021, 16/63, 1105-1118

\title{
NBA Takımlarının Maaş Bütçelerinin Sportif Başarıya Etkisi ${ }^{1}$
}

\section{The Effect of NBA Teams' Salary Budgets on Sportive Success}

\author{
İbrahim Yaşar GÖK, Süleyman Demirel Üniversitesi, Türkiye, ibrahimgok@sdu.edu.tr \\ Orcid No: 0000-0003-3941-1512
}

Türker TEKER, Süleyman Demirel Üniversitesi, Türkiye, turkerteker@ sdu.edu.tr

Orcid No: 0000-0002-4692-3439

Bakican TAŞAN, Süleyman Demirel Üniversitesi, Türkiye, bakican.tasan@gmail.com

Orcid No: 0000-0003-4513-9789

\begin{abstract}
Öz: NBA, dünyantn en bilinen ve en rekabetçi profesyonel basketbol ligi olup, Kuzey Amerika'dan 30 takımı bünyesinde barındırmaktadır. Rekabeti temin etmek adına, NBA, takımlara bir maaş tavanı getirmiştir. Ancak bu katı bir tavan olmayıp, bazı muafiyetlerle aşılabilmektedir. Öte yandan, bir vergi seviyesi de bulunmakta olup, eşik değeri aşan takımlar lüks vergisi ödemekle yüzleşmektedir. NBA'de bir yumuşak maaş tavanının benimsenmesi, takımların maaş bütçeleri arasında bir farklllaşmayı netice vermektedir. Bu çalışma, takım maaş bütçesinin sportif başarı üzerine etkisine ışık tutmaktadır. Başarı, iki kriter etrafinda belirlenmiş olup, bunlardan birisi NBA play-off'larına kattlmak, diğeri ise konferans yarl finallerine yükselmektir. 2010-2011 ile 2018-2019 arası 9 sezon verileri kullanılarak ve bağımsız örneklem t-testi ile Mann-Whitney U testleri uygulanarak ampirik bir araştırma gerçekleştirilmiştir. Buna göre, play-off'lara kalan ve kalamayan takımların maaş bütçeleri arasında istatistiksel olarak anlamlı bir farklılık olduğu bulunmuștur. Bununla beraber, play-off ilk turda elenen takımlar ile konferans yarı finallerine yükselen takımların maaş bütçeleri arasinda istatistiksel olarak anlamlı bir farklılık olmadığı belirlenmiştir. Üstelik, maaş bütçesi sıralaması her ne olursa olsun, eğer bir takım play-off'lara kalabildiyse, konferans finallerine kadar rahatlkkla yükselebileceği tespit edilmiștir. Diğer yandan, 9 sezondaki konferans şampiyonu takımlardan 11 tanesi, maaş bütçesi siralamasında ilk 5 'te yer alan takımlar arasından çıkmıştır. Bundan ötürü, maaş bütçesinin özellikle play-off'lara katılmak ve NBA finalistliği anlamında bir etkiye sahip olduğu, ancak sportif başarı açısından her şey olmadı̆̆ sonucuna varılmıştır.
\end{abstract}

\section{Anahtar Kelimeler: NBA, Takım Maaş Bütçesi, Sportif Başarı}

\section{JEL Sinuflandirması: L83, Z23, Z28}

Abstract: NBA is the world's most known and competitive professional basketball league, which consists of 30 North American teams. To ensure the competitiveness, NBA brought a team salary cap, which is not a hard cap though since the cap can be exceeded under some exceptions. However, there is also a tax level, and if a team exceeds the threshold it would be required to pay luxury taxes. The adoption of a soft cap rule allows some differentiation between team salary budgets. This study explores the impact of team salary budgets on sportive success. The success is determined in terms of two criteria. The first one is participating the NBA playoffs and the second one is advancing to conference semi finals. By using nine seasonal data between 2010-2011 and 20182019 and employing independent sample t-test along with Mann-Whitney $U$ test, an empirical research is conducted. It is found that team salary budgets are significantly different between playoff and non-playoff teams. However, team salary budgets are not statistically different between the teams advancing to conference semi finals and eliminating in the first playoff series. Moreover, it is detected that if a team has participated in playoffs, no matter what its budget ranking is, can advance to conference finals. On the other hand, 11 conference champions out of 9 seasons are emerged from the teams which had at least the 5th position in budget ranking. Therefore, it is concluded that the team salary budget is something, especially for participating the playoffs and being an NBA finalist, but not everything for sportive success.

Keywords: NBA, Team Salary Budget, Sportive Success

JEL Classification: L83, Z23, Z28

\footnotetext{
${ }^{1} \mathrm{Bu}$ çalışma, 07-09 Kasım 2020 tarihlerinden düzenlenen 18. Uluslararası Spor Bilimleri Kongresi'nde sunulmuş ve özet metin olarak basılmıștır.
}

Makale Gecmiși / Article History

Başvuru Tarihi / Date of Application : : 26 Şubat / February 2021

Kabul Tarihi / Acceptance Date $\quad$ : 5 Mayıs / May 2021 


\section{Giriş}

Basketbol, 1891 yllında Springfield, Massachusetts'te Dr. James Naismith tarafindan vakit geçirmek amaciyla sadece 13 kuraldan oluşan bir oyun (Arcgis.com 2020) olarak tasarlanmış iken, zaman içerisinde giderek profesyonelleşmiş ve günümüzde başta Kuzey Amerika olmak üzere Dünya'nın en popüler sporlarından biri haline gelmiştir. Dünya'nın en çok takip edilen ve en büyük ekonomik büyüklüğe sahip basketbol ligi ise ABD'de bulunan Ulusal Basketbol Birliği (National Basketball Association, NBA)'dir. Lig, esasen 1946 y1lında Amerika Basketbol Birliği (Basketball Association of America) adıyla 11 takımla kurulmuş, 1949 yılında Amerika'daki bir diğer lig olan Ulusal Basketbol Ligi (National Basketball League, NBL)'nden 6 takımın katılımıyla hem şsimdiki ismini almış hem de takım sayısı 17'ye yükselmiştir (NBA 2020a). Özellikle NBL'den gelen takımların yaşadığı mali sorunlar sebebiyle, ilk 6 senede 9 takım ligden ayrılmış ve 1955-1961 arasında lig sadece 8 takımla devam etmiştir. 1961 yılında Chicago Packers 9. takım olarak lige dahil olmuş ve 1966'dan 2004'e kadar 21 takımın daha katılmasıyla lig giderek genişlemiştir (NBA Hoops Online 2020). Mevcut durumda, ligde, Doğu ve Batı olmak üzere 15'er takımlı iki konferans bulunmakta olup, Doğu konferansı; Atlantik, Merkez, Güneydoğu gruplarından, Batı konferansı ise Kuzeybat1, Güneybatı ve Pasifik gruplarından oluşmaktadır (ESPN 2020).

Tablo 1. NBA Takım Listesi

\begin{tabular}{|l|l|l|}
\hline \multicolumn{1}{|c|}{ Atlantik } & \multicolumn{1}{c|}{ Moğu Konferansı } \\
\hline Boston Celtics & Chicago Bulls & \multicolumn{1}{c|}{ Güneydoğu } \\
\hline Brooklyn Nets & Cleveland Cavaliers & Chlanta Hawks \\
\hline New York Knicks & Detroit Pistons & Miami Heat \\
\hline Philadelphia 76ers & Indiana Pacers & Orlando Magic \\
\hline Toronto Raptors & Milwaukee Bucks & Washington Wizards \\
\hline \multicolumn{2}{|c|}{ Batı Konferansı } \\
\hline \multicolumn{1}{|c|}{ Kuzeybatik } & \multicolumn{1}{c|}{ Güneybatı } \\
\hline Denver Nuggets & Golden State Warriors & Dallas Mavericks \\
\hline Minnesota Timberwolves & LA Clippers & Houstın Rockets \\
\hline Oklahoma City Thunder & Los Angeles Lakers & Memphis Grizzlies \\
\hline Portland Trail Blazers & Phoenix Suns & New Orleans Pelicans \\
\hline Utah Jazz & Sacramento Kings & San Antonio Spurs \\
\hline
\end{tabular}

Kaynak: (ESPN 2020)

NBA, dünyanın en popüler spor organizasyonlarından biri olmasının yanı sıra, yarattığı ekonomik büyüklük ile aynı zamanda önemli bir ticari organizasyon olarak görülmektedir. 2018-2019 sezonu itibarıla ligdeki 30 takım, yıllık toplam 8,76 milyar USD gelir elde etmişken, bu gelirlerin 1,3 milyar USD'si sponsorluk gelirlerinden oluşmuştur (Gough 2020a). Ortalama bilet fiyatlarının 55,88 USD ile tarihi zirve yaptığı 2015-2016 sezonunda bile, her NBA maçı için ortalama 17.849 bilet satılmıştır (Statista 2016). Pandemi döneminde lig maçları 
seyircisiz bile oynansa, maçlar tüm dünyada, televizyon yayınları ve internet yayıncılığı aracılığıyla 215 ülkede ve 48 ayrı dilde yayınlanmıştır (Insidesport 2020). Forbes dergisinin yayınladığ 1 en çok kazanan sporcular listesinde, 2020 yılında ilk 10'da 3 NBA oyuncusu, ilk 100 'de ise 35 NBA sporcusu yer almaktadır (Badenhausen, Settimi ve Becoats, 2020). Bu durum, ligin sahip olduğu ekonomik büyüklüğün oyuncu maaşlarına da yansıdığının bir göstergesidir.

NBA, dünyadaki profesyonel basketbol oyuncularından birçoğunun hayallerini süslemektedir. Bunun arka planında, hem NBA'deki oyun kalitesi ve yüksek rekabet hem de oyuncuların ortalama olarak milyonlarca USD yıllık maaş elde etmeleri yatmaktadır. Öte yandan, NBA takımları kendi aralarındaki rekabette daha öne çıkmak için tamamı süper yıldız oyunculardan kurulu bir kadroya da sahip olamazlar. Zira, NBA takımlarının maaş bütçeleri için sınırlandırmalar söz konusudur. Üstelik draft uygulamaları da rekabette geri kalmış takımlar lehine kurallara sahiptir. Bu çerçevede, NBA organizasyonu kendi içerisinde bir mali disipline ve getirilen kurallar perspektifinde etkin bir rekabete sahne olmaktadır. Bununla beraber, her takım kendi gelir ve giderlerine sahiptir ve takımların maaş sınırlandırmaları da katı değil esnek bir uygulamaya sahip olduğu için, takımların maaş bütçeleri de belli ölçüde birbirinden farklılaşabilmektedir. Nitekim bu çalışmanın amacı da maaş bütçeleri ile sportif başarı arasındaki ilişkiyi tahlil etmektir. Çalışmada ele alınan bu araştırma konusu, daha önce araştırmacılarca ampirik olarak analiz edilmediğinden, çalışma özgün bir değere sahiptir ve spor finansı literatürüne katkı sağlayacağı düşünülmektedir. Çalışmanın devamında, ikinci bölümde NBA sezon kuralları, NBA takımları maaş bütçesi kuralları ve NBA draft sistemi açıklanmış, üçüncü bölümde ise araştırma dizaynı bağlamında veri seti ve metodoloji ile araştırma bulguları sunulmuştur. Çalışma sonuç bölümüyle tamamlanmaktadır.

\section{NBA'de Sezon, Takım Maaş Bütçesi ve Draft Kuralları}

\subsection{Sezon Kurallart}

NBA'de maç takvimi, normal sezon ve play-off olarak 2 bölümden oluşmaktadır. Her yı1 Ekim² ayında başlayan ve her takımın 82 maç $^{3}$ oynadığı normal sezon, Nisan ayında sona ermektedir (NBA 2020b). Normal sezonun tamamlanmasıyla, play-off turları başlamakta ve bu turnuvayla NBA şampiyonu belirlenmektedir. Play-off aşamasında; konferans ilk tur maçları, konferans yarı finalleri ve konferans finalleri gerçekleştirilip, sonrasında konferans şampiyonları NBA şampiyonluğu için mücadele etmektedir.

\footnotetext{
2 2019-2020 sezonunun pandemi nedeniyle 2020 yılı Ekim ayında sona ermesinden ötürü, 2020-2021 sezonu, bir istisna olarak, 22 Aralık 2020 itibariyle başlayacaktır.

3 2020-2021 sezonunda bir istisna olarak, normal sezonda her bir takım 72 maç oynayacaktır.
} 
Play-off'daki tüm seriler, 4 galibiyet alanın kazanacağı, azami 7 maç üzerinden oynanmaktadır. Normal sezonda kazanma yüzdesi daha yüksek olan takım, playoff serilerinde iç saha avantajına sahip olur. Kazanma yüzdesi, kazanılan maç sayısının toplam maç sayısına bölünmesiyle hesaplanır. 2-2-1-1-1 saha sıralamasıyla oynanan play-off serilerinde, serinin 7 maça uzaması halinde iç saha avantajına sahip olan takım, 4 maça ev sahipliği (1-2-5-7. maçlar) yapmaktadir.

Play-off ilk turunda, her bir konferanstan normal sezonun ilk 8 takımı 2'şerli eşleşmektedir. Bu eşleşme, 1.-8., 2.-7., 3.-6. ve 4.-5. takımlar şeklinde gerçekleşmektedir. İlk tur eşleşmelerden başarılı olanlar, konferans yarı finaline yükselirken, konferans yarı finalinde rakiplerine üstünlük sağlayan iki takım konferans finaline yükselmektedir. Konferans finallerinde başarılı olan takım ise NBA finalinde mücade etmektedir. NBA finali dahil playoff aşamasında, toplamda, minimum 60, maksimum 105 maç oynanabilir (Zhang 2019).

\subsection{Takımların Maaş Bütçesi ile İlgili Kurallar}

NBA'deki takımlar kadrolarında 15 oyuncu bulundurabilirken, bunlardan sadece 13'ünü aktif olarak maç kadrosuna alabilirler (NBA 2020b). Takım kadrolarının oluşturulması aşamasında ligde dengeyi sağlamak amacıyla uygulanan ve açıklanması gereken iki kavram 'maaş tavanı (salary cap)' ve 'draft' sistemidir.

Maaş tavanı, NBA'de yer alan her takımın yıllık toplam ücret harcamalarına bir sınırlama getirilmesi olup, uygulama ilk olarak 1983'te kararlaştırılmıştır. Örneğin; NBA yönetimi tarafindan 2019-2020 sezonu için belirlenen maaş tavanı tutarı 109,1 milyon USD'dir (NBA 2020c). Uygulama sayesinde, takımlar aynı anda çok sayıda süper yıldız oyuncuyla kontrat imzalayamazlar ki bu da ligin rekabetçi yapısının güçlenmesini sağlar (Mola 2001). Öte yandan, NBA maaş tavanı 'katı' bir şekilde de uygulanmayıp bazı esnekliklere de sahiptir.

$\mathrm{Bu}$ esneklikler, NBA toplu iş sözleşmesi (collective bargaining agreement, CBA) çerçevesinde ortaya çıkmaktadır. Sözleşme, NBA'deki tüm profesyonel basketbol oyuncularının istihdam koşul ve şartlarının belirlemekte, kulüpler, oyuncu birliği ve NBA'nın hak ve yükümlülüklerini düzenlemektedir. Mevcut sözleşme, 1 Temmuz 2017'de yürürlüğe girmiş olup, 2023-2024 sezonuna kadar yürürlükte kalacaktır (NBPA 2020). Bu sözleşme kapsamında, kulüplerin oyunculara önerebileceği farklı kontrat türleri sayesinde maaş tavanı k1sitı esnetilebilmektedir.

Sözleşme çerçevesindeki muafiyetler incelendiğinde (CBA Breakdown 2020; NBA 2020d);

- Kidemli serbest oyuncu muafiyeti (veteran free agent): Bu muafiyet kendi içerisinde bird, early bird ve non-bird olmak üzere üç türe sahiptir. Bird terimi, adını, bu muafiyetin ilk kez uygulandığı oyuncu Larry Bird'den almaktadır. Bird muafiyetinde, bir takım, 
kendisinde en az üç sezon oynamış serbest oyuncusuyla, oyuncunun ilk yıl maaşı, maksimum oyuncu maaşı kadar olmak üzere kontrat yapabilmektedir. Early bird muafiyetinde ise, kulüp, kendisinde en az iki sezon oynamış serbest oyuncusuyla, oyuncunun ilk yıl maaşı, önceki kontratının son senesinde aldığı maaşın \%175'ine kadar ya da NBA ortalama oyuncu maaşının \%105'ine kadar olmak üzere (hangisi daha yüksekse), en az iki yıllık kontrat yapabilmektedir. Non-bird muafiyeti ise bir takımın, bird ve early bird dışı oyuncular haricindeki sınırlı serbest oyuncularıyla, oyuncunun ilk yıl maaşı, oyuncunun önceki kontratının son senesindeki maaşının \%120'sine ya da minimum oyuncu maaşının \%120’sine kadar olmak üzere kontrat yapabilmektedir.

- Oyuncu değiş tokuş muafiyeti (traded player): Bu muafiyet, CBA'nın en ilgi çekici bölümü olup, takımlar oyuncuları kendi aralarında değiştirerek, maaş tavanını aşabilmektedirler. Bir takım bu yolla bir yandan diğer takıma maaş göndermekte iken, beri yandan diğer takımdan maaş ödemesi almaktadır. Bir takımın geri alabileceği maaş; takımın maaş tavanını aşmamış olması, maaş tavanını aşmış ama vergi seviyesini aşmamış olması ve hem maaş tavanı hem de vergi seviyesini aşmış olmasına göre değişebilmektedir. Değiş tokuş, eş anlı olabileceği gibi eş anlı olmayan bir şekilde de gerçekleştirilebilmektedir.

- Vergi ödemeyen takım orta seviye maaş muafiyeti (non-taxpayer mid-level salary): Bu muafiyette, maaş tavanını aşan takım, muafiyetin kullanılmasıyla vergi seviyesi ve vergi apronunu ${ }^{4}$ aşmamaktadır. Takım, bir ya da daha fazla oyuncuyla, toplamda izin verilen miktarı (2019-2020 sezonu için 9,25 milyon USD) aşmamak üzere kontrat yapabilir. Bu yöntem, değiş tokuş yoluyla oyuncu elde etmek üzere kullanılamaz.

- Vergi ödeyen takım orta seviye maaş muafiyeti (taxpayer mid-level salary): $\mathrm{Bu}$ muafiyette, maaş tavanının üzerindeki takım muafiyetten yararlanarak, vergi seviyesi ve vergi apronunu aşabilmektedir. Bir ya da daha fazla oyuncuyla, toplamda izin verilen miktarı (2019-2020 için 5,71 milyon USD) aşmamak üzere üç yıla kadar kontrat yapilabilmektedir.

- Oda muafiyeti (room exception): Bu muafiyet, yılın her hangi bir zamanında maaş tavanını aşmamış olmak ve 'iki-yılda-bir', 'vergi ödemeyen takım orta-seviye maaş’ ve 'vergi ödeyen takım orta-seviye maaş' muafiyetlerini kullanmamış olmak kaydıyla kullanılabilir. Bir ya da daha fazla oyuncuyla, toplamda izin verilen miktarı (2019-2020 için 4,76 milyon USD) aşmamak üzere iki yıla kadar kontrat yapılabilir.

\footnotetext{
${ }^{4}$ 2019-2020 sezonunda lüks vergisi apronu 138,9 milyon USD'dir. Takımlar eğer 'iki-yılda-bir', 'vergi ödemeyen takım orta seviye', 'vergi ödeyen takım orta seviye’ ya da 'imzala-değiş tokuş’ muafiyetlerini kullanmışlarsa, maaş bütçelerinin bu lüks vergisi apronunun altında kalması zorunludur (Spotrac, 2020).
} 
- Çaylak muafiyeti (rookie exception): Bu muafiyet, bir takım velev ki maaş tavanını aşsa bile, ilk round çaylak seçimi için kullanılabilmektedir.

- Minimum oyuncu maaşı muafiyeti (minimum player salary exception): Bu muafiyette bir takım, bir oyuncuyla bir ya da iki yıllık bir kontratı, uygulanabilir minimum ücretten yapmaktadır. Bu muafiyet, oyuncuyu değiş tokuş yoluyla elde etmek üzere kullanılabilir. Sezonun ilk gününden sonra muafiyet, orantısal olarak kullanılır.

- Sakat oyuncu muafiyeti (disabled player exception): Sezonu sakatlıkla tamamlayacak bir oyuncu varsa, bu oyuncunun mevcut maaşının \%50'si kadar ya da vergi ödemeyen takım orta-seviye maaş muafiyetinden az maaşlı olmak üzere, bir başka oyuncuyla bir sezonluk bir kontrat yapılabilir.

- İki-yılda-bir muafiyeti: $\mathrm{Bu}$ muafiyet ardışık sezonlarda kullanılamaz. Muafiyet kapsamında bir ya da daha fazla oyuncuyla, toplamda izin verilen miktarı (2019-2020 için 3,62 milyon USD) aşmamak üzere, 2 yıla kadar sözleşme yapılabilir. Muafiyetin uygulanabilmesi için, takım, maaş tavanını aşmış, fakat muafiyet kullanılırken vergi seviyesi ve vergi apronunu aşmamış olması gerekir. Ayrıca muafiyetin kullanılabilmesi için oda muafiyeti ve vergi ödeyen takım orta-seviye maaş muafiyetinin kullanılmamış olması gerekmektedir.

Maaş tavanı sisteminin bir bileşeni olan ve takımları maaş bütçesi hususunda sınırlayan bir uygulama ise lüks vergisidir. NBA'da takımlar, normal maaş tavanının yukarısında belirlenen bir vergi seviyesini (tax level) aşmaları halinde, NBA'ya yıllık bir vergi ödemek zorunda kalmaktadır. Örneğin, 2019-2020 sezonunda vergi seviyesi 132,62 milyon USD olarak belirlenmiştir (NBA 2020c). Vergi ödemeleri, eşik değerin üzerindeki her miktar için standart bir oran üzerinden değil, eşik değerin üzerindeki miktarlar için çeşitli dilimler oluşturulması ve yukarı her dilimde daha yüksek bir vergi ödenmesi şeklinde tasarlanmıştır. Dolayısıyla, lüks vergisinde artan bir tarife söz konusu olup, eşik değeri daha çok aşmanın daha yüksek maliyetleri söz konusu olmaktadır. Eşik değerin;

- 4.999.999 USD’ye kadar aşılması halinde aşılan her 1 USD için 1,5 USD,

- 5.000.000 USD - 9.999.999 USD arasında aş1lan her 1 USD için 1,75 USD,

- 10.000.000 USD - 14.999.999 USD arasında aşılan her 1 USD için 2,5 USD,

- 15.000.000 USD - 19.999.999 USD arasında aşılan her 1 USD için 3,25 USD,

- 20.000.000 USD - 24.999.999 USD arasında aşılan her 1 USD için 3,75 USD vergi olarak ödenmekte olup, 25 milyon USD'nin üzerindeki her 5 milyon USD’lik dilim için vergi 0,5 USD artmaktadır. (Urbina 2018). 
Örneğin bir takım eşik değeri 12 milyon USD aşmışsa, 4.999.999'a kadar olan kısım için 7,5 milyon USD, 5 ila 9,999 milyonluk dilim için 8,75 milyon USD ve 10 milyondan sonraki 2 milyon USD için de 5 milyon USD olmak üzere, toplamda 21,25 milyon USD $(7,5+8,75+5)$ vergi ödeyecektir.

Bunun yanı sıra, maaş tavanının \%90’1 da minimum kontrat tutarı olarak belirlenmiş olup, takımlar bu tutarın altında maaş harcaması yapamazlar. Örneğin, 2019-2020 sezonu için minimum takım maaşı 98,22 milyon USD olarak belirlenmiştir (NBA 2020c). 2019-2020 sezonunda NBA takımları, maaşlar için yaklaşık olarak ortalama 125 milyon USD harcamıştır (Spotrac 2020). 2019-2020 sezonunda sadece dört takım lüks vergisi ödemiş olup, bu dört takım toplamda 5 milyon USD’ye yakın bir ödeme gerçekleştirmiştir (Thunder Wire 2020). NBA takımlarından, şimdiye kadar en fazla sayıda lüks vergisi ödeyen takım, 10 kere ödemeyle New York Knicks olup, bu takım toplamda 248,5 milyon USD ödeme yapmıştır (Hoops Hype 2018).

NBA'de oyunculara ödenecek minimum ücret tutarı, tecrübeyle doğru orantılı olarak saptanmaktadır. Dolayısıyla bir oyuncunun NBA'daki tecrübesi arttıkça elde edebileceği minimum maaş da artmaktadır. Bu uygulamanın arka planında ise takımların kıdemli oyuncuları, genç ve daha ucuz oyuncularla değiştirmemesi düşüncesi yatmaktadır (Hoops Rumors 2019). Nitekim 2019-2020 sezonunda daha önce NBA tecrübesi olmayan bir oyuncunun alabileceği minimum yıllık ücret 898.310 USD iken, 9 yıllık tecrübeye sahip bir oyuncunun minimum maaşı ise 2.3 milyon USD civarındadır (Hoops Rumors 2019). 20192020 sezonunda NBA'de ki ortalama oyuncu maaşı 8,32 milyon USD iken, bu sezonda oyunculara ödenen toplam maaşlar 3,67 milyar USD civarında olmuştur (Gough 2020b).

\subsection{Draft Sistemi}

Gerek Amerika üniversite liginden, gerekse Dünya’nın çeşitli liglerinden kendilerine güvenen genç oyuncular, Draft adı verilen sisteme kendi adlarına başvuru yaparak NBA seçmelerine katılma imkanı elde ederler. Draft sistemi, güçsüz takımlarla güçlü takımlar arasında denge sağlayarak rekabeti artırma amacı taşımaktadır. Buna göre takımlar, belli kurallar çerçevesinde oluşturulan bir sıralama doğrultusunda, lige katılmak isteyen oyuncular arasından takımlarına oyuncu seçme hakkına sahip olurlar. İlk draft uygulaması 1947 yılında başlamıştır (NBA 2020e). Draft kuralları zaman içerisinde çeşitli değişiklikler göstermiştir.

Draftlarda 1. ve 2. tur uygulamas1 mevcuttur. Her yıl draftlarda, takımlar, 1. ve 2. turda 1'er tane olmak üzere toplam 2 oyuncu seçme hakkına sahiptir. Dolayısıyla, 1 ve 2. turlarda toplamda 30'ar tane oyuncu seçilecektir. Play-offlara katılamayan 14 takım, ilk turda ilk 14 oyuncuyu seçecektir. Bu 14 takımdan hangisinin ilk 4 oyuncuyu seçeceği kura ile belirlenecektir (NBA 2020f). Bu takımlar ağırlıklandırılmış bir sistemle 'draft kurası' adı 
verilen bir çekilişe katılarak ilk sıralarda kendilerine yer bulmaya çalışırlar. Normal sezonda en çok mağlubiyet alan 3 takımdan birinin ilk sırayı elde etme ihtimali daha yüksektir (Doğan 2020).

2019 itibariyle yürürlüğe giren son değişiklikle, en kötü sıralamaya sahip takımın en azından 5. sıradan oyuncu seçmesi kuralı getirilmiştir. En kötü üç performansa sahip takımın kurayı kazanma olasılığı da yeni uygulamayla aynı yüzdeye getirilerek, en kötü üç takımın her birinin kurayı kazanma olasılığı \%14'tür. İlk dört seçim için kuralar çekildikten sonra, kalan diğer kura takımları, sezon başarılarıyla ters orantılı bir şekilde oyuncu seçeceklerdir. İlk turun kalan 16 oyuncusu (15-30) ile ikinci turdaki 30 oyuncu için takımlar sezon başarıları ile ters orantılı bir şekilde oyuncu seçmektedirler (NBA 2020f).

Kadrolar oluşturulurken takımlar, bir önceki sezon kadroda olan oyuncularla devam edebilir, draft sistemiyle 2 yeni genç oyuncu seçimi yapabilir ya da daha önce NBA'de oynamamış olup ta şartları sağlayan oyunculara draft dışı doğrudan kontrat da önerebilirler. Nitekim, bir oyuncu 23 yaşın üzerindeyse ve geçmişte herhangi bir takım tarafından draft edilmemişse, NBA takımları bu oyuncuyu, doğrudan kontrat önererek kadrolarına katabilir. Hatta 750.000 USD’yi aşmamak kaydıyla bu oyuncular için bonservis ödemesi de yapabilir. Örneğin; Brad Wanamaker'in Fenerbahçe Beko'dan Boston Celtics'e 2018 yılındaki transferi bu yöntemle gerçekleştiği gibi, Malcolm Delaney de yine bu yöntemle NBA'de kontrat almış bir oyuncudur (Kural 2020).

\section{Araştırma Dizaynı}

\subsection{Veri Seti ve Metodoloji}

$\mathrm{Bu}$ çalışmanın amacı, NBA takımlarının elde ettikleri sportif başarıların, takım maaş bütçesinden etkilenip etkilenmediğini incelemektir. Çalışmada kullanılan veri seti, 2010-2011 ile 2018-2019 arasındaki 9 sezonu kapsamaktadır. Veri setinde, 30 takıma ait sezonluk maaş bütçeleri ile sezonluk başarı verileri yer almaktadır. Başarı, 2 kriter etrafında belirlenmiştir. Bunlardan birisi play-off'lara katılabilmek, diğeri ise play-off'larda konferans yarı finaline yükselebilmektedir. İlk kriterde 30 takımdan, play-off'a katılabilen 16 takım 'başarılı' ve katılamayan 14 takım ise ‘başarısız' olarak kategorize edilmiştir. İkinci kriterde ise play-off ilk turunda rakiplerini yenerek konferans yarı finaline çıkan 8 takım 'başarılı' ve play-off ilk turda elenen 8 takım ise ‘başarısız’ olarak kategorize edilmiştir.

$\mathrm{Bu}$ iki başarı kriteri etrafında, takımların maaş bütçelerinde anlamlı bir fark olup olmadığı parametrik bağımsız örneklem t-testi ve non-parametrik Mann-Whitney U testi kullanılarak araştırılmıştır. Ayrıca NBA şampiyonu ve konferans finalistlerinin, ilgili sezondaki bütçe sıralaması etrafında bazı değerlendirmelerde bulunulmuştur. NBA kulüplerinin yıllık 
bütçelerine ilişkin veri setinin hazırlanmasında, 'Hoops Hype' isimli web sitesinden yararlanılmıştır (Hoops Hype 2020). Kulüplerin yıllar itibariyle sergiledikleri başarılara ilişkin veriler, 'Basketball Reference' isimli web sitesinden derlenmiştir (Basketball Reference 2020).

Tablo 2. Başarı Kriterleri

\begin{tabular}{|l|c|c|}
\hline & Play-off'a Katılabilme & $\begin{array}{c}\text { Play-off'larda Konferans } \\
\text { Yarı Finaline Katılabilme }\end{array}$ \\
\hline Katılan & 16 Takım (Başarıl1) & \multicolumn{2}{|c|}{ Takım (Başarılı) } \\
\hline Katılamayan & 14 Takım (Başarısız) & 8 Takım (Başarısız) \\
\hline
\end{tabular}

\subsection{Araştırma Bulguları}

Analize parametrik ya da parametrik olmayan yöntemlerle devam etme noktasında karar verme aşamasında serilerin normal dağılım gösterip göstermediği belirleyici faktördür. Normal dağılım sergileyen seriler için yapılacak analizlerde parametrik testler kullanılırken, eğer seriler normal dağılmıyorsa parametrik olmayan testler tercih edilmelidir. Bu bağlamda, bütçe verilerinin normal dağılımı gösterip göstermediği, Kolmogorov-Smirnov ve Shapiro Wilk testleriyle sınanmıştır. Sonuçlar, Tablo 3.'te sunulmuştur. Buna göre, veri setinde yer alan 9 sezondan 7 tanesinde seriler normal dağılım göstermekte iken, 2012-2013 ve 2013-2014 sezonlarındaki bütçe verileri normal dağılım göstermemektedir.

Tablo 3. Normallik Testi Sonuçları

\begin{tabular}{|c|c|c|c|c|c|c|c|}
\hline \multicolumn{4}{|c|}{ Kolmogorov-Smirnov } & \multicolumn{3}{c|}{ Shapiro-Wilk } & \multirow{2}{*}{$\begin{array}{l}\text { NORMAL } \\
\text { DAĞILIM }\end{array}$} \\
\cline { 1 - 7 } Sezon & İstatistik & Frekans & Olasılık & İstatistik & Frekans & Olasılık & \\
\hline $\mathbf{2 0 1 0 - 2 0 1 1}$ & 0,144 & 30 & 0,114 & 0,949 & 30 & 0,164 & Evet \\
\hline $\mathbf{2 0 1 1 - 2 0 1 2}$ & 0,113 & 30 & 0,200 & 0,966 & 30 & 0,437 & Evet \\
\hline $\mathbf{2 0 1 2 - 2 0 1 3}$ & 0,193 & 30 & $\mathbf{0 , 0 0 6}$ & 0,923 & 30 & $\mathbf{0 , 0 3 3}$ & Hayır \\
\hline $\mathbf{2 0 1 3 - 2 0 1 4}$ & 0,131 & 30 & 0,199 & 0,914 & 30 & $\mathbf{0 , 0 1 8}$ & Hayır \\
\hline $\mathbf{2 0 1 4 - 2 0 1 5}$ & 0,115 & 30 & 0,200 & 0,955 & 30 & 0,231 & Evet \\
\hline $\mathbf{2 0 1 5 - 2 0 1 6}$ & 0,144 & 30 & 0,116 & 0,951 & 30 & 0,176 & Evet \\
\hline $\mathbf{2 0 1 6 - 2 0 1 7}$ & 0,091 & 30 & 0,200 & 0,971 & 30 & 0,579 & Evet \\
\hline $\mathbf{2 0 1 7 - 2 0 1 8}$ & 0,110 & 30 & 0,200 & 0,964 & 30 & 0,387 & Evet \\
\hline $\mathbf{2 0 1 8 - 2 0 1 9}$ & 0,138 & 30 & 0,150 & 0,949 & 30 & 0,157 & Evet \\
\hline
\end{tabular}

Normal dağılım gösteren serilere ilişkin olarak bağımsız örneklem t-testi uygulanmış iken, normal dağılım göstermeyen seriler için Mann-Whitney U testi kullanılmıştır. Sınanan sıfır hipotezi, 'başarılı ve başarısız takımların bütçeleri arasında istatistiksel olarak anlamlı bir farkl1lık yoktur' şeklindedir. Elde edilen bulgular, Tablo 4'te sunulmuştur. Buna göre;

- Play-off'a katılan ve katılmayan takımların bütçeleri arasında, 9 sezonun 5'inde (20102011, 2011-2012, 2012-2013, 2015-2016, 2017-2018) \%5 anlamlilik seviyesinde, 1 sezonda (2013-2014) ise \%10 anlamlılık seviyesinde istatistiksel olarak anlamlı bir farklılık bulunmaktadır. Dolayısıyla, play-off’a katılabilme başarı ölçütü etrafında, 9 sezonun 
toplamda 6'sında sıfır hipotezi reddedilmektedir. Bu 6 sezondaki başarılı ve başarısız takımların her bir sezondaki ortalama bütçeleri ya da ortalama sıra değerleri incelendiğinde; 2010-2011 sezonunda play-off’a katılan 16 takımın ortalama bütçesi 84,4 milyon USD iken, katılamayan 14 takımın ortalama bütçesi 73,6 milyon USD'dir. 2011-2012 sezonunda playoff'a katılan 16 takımın ortalama bütçesi 80,5 milyon USD iken, katılamayan 14 takımın ortalama bütçesi 71,4 milyon USD'dir. 2012-2013 sezonunda play-off'a katılan 16 takımın ortalama sıra değeri 19,63 iken, katılamayan 14 takımın ortalama sıra değeri 10,79'dur. 2013-2014 sezonunda play-off'a katılan 16 takımın ortalama sıra değeri 18,25 iken, katılamayan 14 takımın ortalama sıra değeri 12,36'dır. 2015-2016 sezonunda play-off'a katılan 16 takımın ortalama bütçesi 88,7 milyon USD iken, katılamayan 14 takımın ortalama bütçesi 79,1 milyon USD'dir. 2017-2018 sezonunda ise play-off'a katılan 16 takımın ortalama bütçesi 124,9 milyon USD iken, katılamayan 14 takımın ortalama bütçesi 108 milyon USD'dir. Bu bağlamda, 6 sezonun tamamında da, play-off'a katılma başarısı gösteren takımların bütçelerinin ortalamaları (ya da ortalama sıra değerleri), katılamayan takımların bütçelerinin ortalamalarından (ya da ortalama sıra değerlerinden) anlamlı bir şekilde yüksektir. Bu doğrultuda, bütçenin yüksekliğinin, play-off’a katılma başarısına belirgin bir katkı yaptığı anlaşılmaktadır.

- Konferans yarı finaline çıkabilme başarı kriteri etrafında, sezonların tamamında, sıfır hipotezi kabul edilmektedir. Dolayısıyla, play-off ilk turda elenen takımlar ile konferans yarı finaline yükselen takımların bütçeleri arasında istatistiksel olarak anlamlı bir farklılık bulunmamaktadır.

Tablo 4. Bağımsız Örneklem t testi ve Mann-Whitney U Testi Sonuçları

\begin{tabular}{|c|c|c|c|c|c|c|}
\hline Sezon & $\begin{array}{l}\text { Normal } \\
\text { Dağılım }\end{array}$ & Test & Sinıflandırma & $\begin{array}{c}\text { t- } \\
\text { istatistiği/ } \\
\text { z-değeri }\end{array}$ & Anlamlılık & SONUÇ \\
\hline \multirow{2}{*}{$\begin{array}{l}2010 \\
2011\end{array}$} & Evet & $\begin{array}{c}\text { Bağımsız } \\
\text { örneklem t-testi }\end{array}$ & $\begin{array}{c}\text { Play-off'a } \\
\text { Katılım }\end{array}$ & 2,545 & 0,017 & $\begin{array}{c}\text { Anlamlı } \\
\text { Farklılık Var }\end{array}$ \\
\hline & & & $\begin{array}{c}\text { Konferans } \\
\text { Yar1 Finaline } \\
\text { Katılım }\end{array}$ & 0,115 & 0,910 & $\begin{array}{c}\text { Anlamlı } \\
\text { Farklılık Yok }\end{array}$ \\
\hline \multirow{2}{*}{$\begin{array}{l}2011 \\
2012\end{array}$} & Evet & $\begin{array}{c}\text { Bağımsız } \\
\text { örneklem t-testi }\end{array}$ & $\begin{array}{l}\text { Play-off'a } \\
\text { Katılım }\end{array}$ & 2,201 & 0,036 & $\begin{array}{c}\text { Anlamlı } \\
\text { Farklılık Var }\end{array}$ \\
\hline & & & $\begin{array}{c}\text { Konferans } \\
\text { Yar1 Finaline } \\
\text { Katılım }\end{array}$ & $-0,089$ & 0,930 & $\begin{array}{c}\text { Anlamlı } \\
\text { Farklılık Yok }\end{array}$ \\
\hline \multirow[b]{2}{*}{$\begin{array}{l}2012 \\
2013\end{array}$} & Hayır & $\begin{array}{c}\text { Mann-Whitney } \\
\text { U testi }\end{array}$ & $\begin{array}{l}\text { Play-off'a } \\
\text { Katılım }\end{array}$ & $-0,2744$ & 0,005 & $\begin{array}{c}\text { Anlamlı } \\
\text { Farklılık Var }\end{array}$ \\
\hline & & & $\begin{array}{c}\text { Konferans } \\
\text { Yar1 Finaline } \\
\text { Katılım }\end{array}$ & $-0,420$ & 0,721 & $\begin{array}{c}\text { Anlamlı } \\
\text { Farklılık Yok }\end{array}$ \\
\hline $\begin{array}{l}2013 \\
2014\end{array}$ & Hayır & $\begin{array}{c}\text { Mann-Whitney } \\
\text { U testi }\end{array}$ & $\begin{array}{l}\text { Play-off'a } \\
\text { Katılım }\end{array}$ & $-1,829$ & 0,07 & $\begin{array}{c}\text { Anlamlı } \\
\text { Farklılık Var }\end{array}$ \\
\hline
\end{tabular}




\begin{tabular}{|c|c|c|c|c|c|c|}
\hline & & & $\begin{array}{c}\text { Konferans } \\
\text { Yar1 Finaline } \\
\text { Katılım }\end{array}$ & $-0,630$ & 0,574 & $\begin{array}{c}\text { Anlamlı } \\
\text { Farklılık Yok }\end{array}$ \\
\hline \multirow[b]{2}{*}{$\begin{array}{l}2014 \\
2015\end{array}$} & Evet & $\begin{array}{c}\text { Bağımsız } \\
\text { örneklem t-testi }\end{array}$ & $\begin{array}{l}\text { Play-off'a } \\
\text { Katılım }\end{array}$ & 1,627 & 0,115 & $\begin{array}{c}\text { Anlamlı } \\
\text { Farkl1l1k Yok }\end{array}$ \\
\hline & & & $\begin{array}{c}\text { Konferans } \\
\text { Yar1 Finaline } \\
\text { Katılım }\end{array}$ & 0,03 & 0,977 & $\begin{array}{c}\text { Anlamlı } \\
\text { Farklılık Yok }\end{array}$ \\
\hline \multirow[b]{2}{*}{$\begin{array}{l}2015 \\
2016\end{array}$} & Evet & $\begin{array}{c}\text { Bağımsız } \\
\text { örneklem t-testi }\end{array}$ & $\begin{array}{c}\text { Play-off'a } \\
\text { Kat1lım } \\
\end{array}$ & 2,375 & 0,025 & $\begin{array}{c}\text { Anlamlı } \\
\text { Farklılı Var }\end{array}$ \\
\hline & & & $\begin{array}{c}\text { Konferans } \\
\text { Yar1 Finaline } \\
\text { Katılım } \\
\end{array}$ & 0,615 & 0,548 & $\begin{array}{c}\text { Anlamlı } \\
\text { Farklılık Yok }\end{array}$ \\
\hline \multirow{2}{*}{$\begin{array}{l}2016 \\
2017\end{array}$} & Evet & $\begin{array}{c}\text { Bağımsız } \\
\text { örneklem t-testi }\end{array}$ & $\begin{array}{c}\text { Play-off'a } \\
\text { Katılım }\end{array}$ & 1,592 & 0,123 & $\begin{array}{c}\text { Anlamlı } \\
\text { Farklılık Yok }\end{array}$ \\
\hline & & & $\begin{array}{c}\text { Konferans } \\
\text { Yar1 Finaline } \\
\text { Katılım }\end{array}$ & 0,153 & 0,881 & $\begin{array}{c}\text { Anlamlı } \\
\text { Farklılık Yok }\end{array}$ \\
\hline \multirow[b]{2}{*}{$\begin{array}{l}2017 \\
2018\end{array}$} & Evet & $\begin{array}{c}\text { Bağımsız } \\
\text { örneklem t-testi }\end{array}$ & $\begin{array}{c}\text { Play-off'a } \\
\text { Katılım }\end{array}$ & 3,799 & 0,001 & $\begin{array}{c}\text { Anlamlı } \\
\text { Farklılık Var }\end{array}$ \\
\hline & & & $\begin{array}{c}\text { Konferans } \\
\text { Yar1 Finaline } \\
\text { Katılım }\end{array}$ & $-0,039$ & 0,969 & $\begin{array}{c}\text { Anlamlı } \\
\text { Farklılık Yok }\end{array}$ \\
\hline \multirow{2}{*}{$\begin{array}{l}2018 \\
2019\end{array}$} & Evet & $\begin{array}{c}\text { Bağımsız } \\
\text { örneklem t-testi }\end{array}$ & $\begin{array}{c}\text { Play-off'a } \\
\text { Katılım }\end{array}$ & 1,923 & 0,065 & $\begin{array}{c}\text { Anlamlı } \\
\text { Farklılık Yok } \\
\end{array}$ \\
\hline & & & $\begin{array}{c}\text { Konferans } \\
\text { Yar1 Finaline } \\
\text { Katılım }\end{array}$ & 1,478 & 0,162 & $\begin{array}{c}\text { Anlamlı } \\
\text { Farklılık Yok }\end{array}$ \\
\hline
\end{tabular}

NBA finalistliği ve konferans finalistliğinin istatistiksel analize dahil edilmeme nedeni, her sezon yalnızca 2 takımın NBA finali oynaması ve sadece 4 takımın konferans finallerine yükselmesidir. Zira yetersiz veri nedeniyle sağlıklı bir istatistiksel analiz yapılamamaktadır. Bu bağlamda, bu dört takımın ilgili sezondaki bütçe sıralamaları Tablo 5'te derlenerek, bazı bulgulara ulaşılmıştır.

Tablo 5. NBA Konferans Finalistleri ve NBA Finalistlerinin Bütçe Sıralamaları

\begin{tabular}{|c|c|c|c|c|}
\hline \multicolumn{5}{|c|}{ Panel A: NBA Finalistleri } \\
\hline Sezon & NBA Şampiyonu & $\begin{array}{c}\text { Bütçe } \\
\text { Sıralaması }\end{array}$ & NBA Finalisti & $\begin{array}{c}\text { Büitçe } \\
\text { Sıralaması }\end{array}$ \\
\hline $2010-2011$ & Dallas Mavericks & 3 & Miami Heat & 19 \\
\hline 2011-2012 & Miami Heat & 8 & Oklahoma City & 21 \\
\hline $2012-2013$ & Miami Heat & 3 & San Antonio Spurs & 8 \\
\hline 2013-2014 & San Antonio Spurs & 19 & Miami Heat & 3 \\
\hline 2014-2015 & Golden State Warriors & 14 & Cleveland Cavaliers & 4 \\
\hline 2015-2016 & Cleveland Cavaliers & 1 & Golden State Warriors & 4 \\
\hline 2016-2017 & Golden State Warriors & 14 & Cleveland Cavaliers & 1 \\
\hline $2017-2018$ & Golden State Warriors & 2 & Cleveland Cavaliers & 1 \\
\hline 2018-2019 & Toronto Raptors & 4 & Golden State Warriors & 2 \\
\hline
\end{tabular}




\begin{tabular}{|c|c|c|c|c|}
\hline & $\begin{array}{c}\text { Doğu Konferans } \\
\text { Finalisti }\end{array}$ & $\begin{array}{c}\text { Bütçe } \\
\text { Sıralaması }\end{array}$ & $\begin{array}{c}\text { Batı Konferansı } \\
\text { Finalisti }\end{array}$ & $\begin{array}{c}\text { Bütçe } \\
\text { Sıralaması }\end{array}$ \\
\hline $2010-2011$ & Chicago Bulls & 26 & Oklahoma City & 25 \\
\hline $2011-2012$ & Boston Celtics & 5 & San Antonio Spurs & 9 \\
\hline $2012-2013$ & Indiana Pacers & 16 & Memphis Grizzlies & 22 \\
\hline $2013-2014$ & Indiana Pacers & 15 & Oklahoma City & 10 \\
\hline $2014-2015$ & Atlanta Hawks & 26 & Houston Rockets & 10 \\
\hline $2015-2016$ & Toronto Raptors & 24 & Oklahoma City & 3 \\
\hline $2016-2017$ & Boston Celtics & 20 & San Antonio Spurs & 4 \\
\hline $2017-2018$ & Boston Celtics & 15 & Houston Rockets & 8 \\
\hline $2018-2019$ & Milwaukee Bucks & 5 & Portland Trail Blazzers & 6 \\
\hline
\end{tabular}

Kaynak: (Basketball Reference 2020; Hoops Hype 2020).

Buna göre;

- 9 sezonun 5'inde şampiyon, 6'sında ise diğer NBA finalisti takım, maaş bütçe sıralamasında ilk 5 'te yer alan takımlar arasından çıkmıştır.

- 2013-2014 sezonundaki San Antonio Spurs şampiyonluğu hariç, bütçe sıralamasında ilk 14'te yer almayan herhangi bir takım, NBA şampiyonu olamamıştır.

Öte yandan;

- Konferans finalisti olan takımlar, her bütçe seviyesinden takımlar arasından çıkabilmektedir. Örneğin 2010-2011 sezonu doğu konferansı finalisti Chicago Bulls sezonun en düşük 5. bütçeli takımıdır. Yine aynı şekilde 2014-2015 sezonu doğu konferansı finalisti Atlanta Hawks, sezonun en düşük bütçeli 5. takımı olarak dikkat çekmektedir.

\section{Sonuç}

NBA, gerek gelirleri, gerek izleyici kitlesi itibariyle dünyanın en büyük spor organizasyonlarından biridir. Dünyanın en bilinen profesyonel basketbol oyuncularının bu ligde oynamalarının yanı sıra, bu ligi en değerli kılan unsurlardan birisi de takımlar arasındaki etkin rekabettir. Bu rekabeti temin edebilmek adına, NBA bir takım kurallar getirmiştir. $\mathrm{Bu}$ kurallardan birisi takımların maaş tavanları olduğu gibi diğer yandan oyuncuların özlük hakları ve draft sistemi uygulamaları da kaliteyi tetiklemektedir. NBA takımları kendi gelirleri ne kadar olursa olsun sınırsız bir maaş bütçesine sahip olamazlar. Bu bağlamda her sezonda takım maaş tavanı belirlenmektedir. Ancak bu tavan, katı bir şekilde uygulanmayıp, toplu iş sözleşmesindeki bazı muafiyetlerin devreye girmesiyle esnetilebilmektedir. Öte yandan, maaş tavanının daha da yukarısında bir vergi seviyesi de belirlenerek, bu seviyenin aşılması halinde takımlardan lüks vergisi adı altında bir ödeme alınmaktadır. 
Maaş bütçesindeki belli esneklikler, takımların maaş bütçeleri arasında bazı farklılaşmaları netice vermektedir. $\mathrm{Bu}$ araştırmanın konusu da NBA takımlarının maaş bütçelerindeki farklılaşmanın sportif başarıya etkisinin tespit edilmesidir. Bu bağlamda 2010-2011 ve 20182019 arası 9 sezonun verileri kullanılarak ampirik bir araştırma gerçekleştirilmiştir. Başarı kriteri olarak iki ölçüt benimsenmiştir. Bunlardan birisi takımların NBA play-off'larına katılmasıdır. Diğeri ise, play-off ilk tur maçlarında rakiplerin elenerek konferans yarı finaline çıkılmasıdır. Bu iki ölçüt etrafında her bir sezon için başarılı ve başarısız takımlar şeklinde kategorik veriler oluşturulmuştur. Başarı kriterleri ile bütçe arasındaki ilişki, bağımsız örneklem t-testi (ya da parametrik olmayan Mann-Whitney U testi) kullanılarak analiz edilmiştir. Elde edilen bulgular, iki başarı kriterinden sadece bir tanesinin kayda değer bir şekilde takımın maaş bütçesiyle ilişkili olduğuna işaret etmektedir. Bu kriter ise takımın playoff'lara katılması ya da katılmamasıdır. Gerçekten incelenen dokuz sezonun altısında, başarılı ve başarısız takımların maaş bütçeleri arasında istatistiksel olarak anlamlı farklılıklar olduğu tespit edilmiş ve takımların maaş bütçesinin artmasının, play-off'lara katılma başarısını da beraberinde getirdiği görülmüştür.

Öte yandan, konferans yarı finaline yükselen ve ilk turda elenen takımların maaş bütçeleri arasında ise anlamlı bir farklılık bulunmamıştır. Dolayısıyla play-off'lara katıldıktan sonraki süreçte, maaş bütçesi büyüklüğü etkisini azaltmaktadır. Gerçekten de bütçesi daha düşük olsa bile, bir şekilde play-off'lara katılabilmiş bir takım, konferans finallerine kadar yükselebilmektedir. Öte yandan, NBA finalistliği ise bütçeyle yakından ilgili gözükmektedir. Nitekim ele alınan 9 sezonun 5'inde şampiyonlar, 6'sında ise NBA finalisti diğer takım, en büyük beş bütçeye sahip takımlar arasından çıkmıştır. Bu çerçevede, bütçe, etkisini özellikle, play-off'lara katılma ve NBA finalistliği anlamında ortaya çıkarmaktadır. Ancak bütçenin de her şey olmadığı gayet açıktır. Zira, her sezonun en büyük bütçeli takımı, sadece 3 kere NBA finallerine yükselirken, bunlardan da sadece 1 tanesinde şampiyon olabilmiştir. Bu sonuç, maaş bütçesinin, başarıyı sağlayıcı birçok faktör içinden sadece bir tanesi olabileceğine işaret etmektedir. 


\section{KAYNAKÇA}

Arcgis.com. (2020). "The expansion of basketboll and the NBA". https://www.arcgis.com/apps/MapJournal/index.html?appid=a24aefcaafaa4a4ca91670e509bd7f5b (Erişim Tarihi: 14.11.2020).

Badenhausen, K., Settimi, C., Becoats, K. (2020). "Highest paid athletes in the world". https://www.forbes.com/athletes/\#57cd0b5155ae (Erişim Tarihi: 29.10.2020).

Basketball Reference. (2020). "NBA \& ABA league index". https://www.basketball-reference.com/leagues (Erişim Tarihi: 30.10 .2020 ).

Doğan, T. (2020). "NBA draft çekilişi sistemi ve sıralama oranları". https://www.sonperiyot.com/nba-draftcekilisi-sistemi-ve-siralama-oranlari/ (Erişim Tarihi: 30.10.2020).

ESPN. (2020). "NBA teams”. https://www.espn.com/nba/teams (Erişim Tarihi: 10.11.2020).

Gough, C. (2020a). "NBA total league revenue from 2001/02 to 2018/19". https://www.statista.com/statistics/193467/total-league-revenue-of-the-nba-since-

2005/\#: :text=In\%20the\%202018\%2F19\%20season,about\%208.76\%20billion\%20U.S.\%20dollars.\&te $\mathrm{xt}=$ The $\% 20$ teams $\% 20$ of\%20the\%20NBA,dollars\%20in\%20the\%202018\%2F19. (Erişim Tarihi: 14.11.2020).

Gough, C. (2020b). "Annual salaries in the NBA in 2019-2020". https://www.statista.com/statistics/1120257/annual-salaries-nba/ (Erişim Tarihi: 16.11.2020).

Hoops Hype. (2018). "How many times has each NBA team paid the luxury tax?". https://hoopshype.com/2018/11/16/how-many-times-has-each-nba-team-paid-the-luxury-tax/ (Erişim Tarihi: 16.11 .2020 ).

Hoops Hype. (2020). "NBA salaries". https://hoopshype.com/salaries/ (Erişim Tarihi: 30.10.2020).

Hoops Rumors. (2019). "NBA minimum salaries for 2019/20". https://www.hoopsrumors.com/2019/06/nbaminimum-salaries-for-201920.html (Erişim Tarihi: 16.11.2020).

Insidesport. (2020). "NBA finals between Lakers vs. Heat to go live in 215 countries, 48 languages". https://www.insidesport.co/nba-finals-between-lakers-vs-heat-to-go-live-in-215-countries-48languages/ (Erişim Tarihi: 17.11.2020).

Kural, K. (2020). 24 Ekim 2020 tarihinde T. Teker tarafindan röportaj yapılmıştır.

NBA. (2020a). "A chronology of the teams in NBA". https://www.nba.com/celtics/history/nba-teams-chronology (Erișim Tarihi: 14.11.2020).

NBA. (2020b). "NBA frequently asked questions". https://www.nba.com/news/faq (Erişim Tarihi: 14.11.2020).

NBA. (2020c). "NBA salary cap set at $\$ 109.14$ million for 2019-20". https://www.nba.com/news/nba-salary-cap2019-20-season-set-10914-million (Erişim Tarihi: 15.11.2020).

NBA. (2020d). "Free agency explained". https://www.nba.com/free-agency-explained (Erişim Tarihi: 16.11.2020).

NBA. (2020e). "All-time NBA draft history". https://www.nba.com/history/draft (Erişim Tarihi: 22.11.2020).

NBA. (2020f). "NBA draft lottery: Schedule, odds and how it works". https://www.nba.com/nba-draft-lotteryexplainer (Erişim Tarihi: 24.10.2020).

NBA Hoops Online. (2020). "NBA history". https://nbahoopsonline.com/History/ (Erişim Tarihi: 14.11.2020).

NBPA. (2020). "Collective bargaining agreement (CBA)". https://nbpa.com/cba (Erişim Tarihi: 16.11.2020).

Mola, G. (2001). "Salary cap denen mucize sistem". http://arsiv.ntv.com.tr/news/20812.asp (Erişim Tarihi: 05.11.2020)

Spotrac. (2020). "NBA team salary cap tracker". https://www.spotrac.com/nba/cap/2019/ (Erişim Tarihi: 27.11.2020).

Statista. (2016). "Average ticket price NBA by team 2015/16 season". https://www.statista.com/statistics/193720/average-ticket-price-in-the-nba-by-team-in-2010/ (Erişim Tarihi: 24.11.2020).

Thunder Wire. (2020). "Thunder among just 4 NBA teams to pay luxury tax for 2019-20 season". https://okcthunderwire.usatoday.com/2020/11/12/thunder-among-just-4-nba-teams-to-pay-luxury-taxfor-2019-20-season/ (Erișim Tarihi: 08.11.2020).

Urbina, F. (2018). "How does the NBA's luxury tax work?". https://hoopshype.com/2018/10/11/nba-luxury-tax/ (Erişim Tarihi: 09.11.2020).

Zhang, L. (2019). "How do the NBA playoffs work?". https://dunkorthree.com/how-nba-playoffs-work (Erişim Tarihi: 19.11.2020). 